\title{
Soil moisture and expectations regarding future climate: evidence from panel data
}

\author{
P. Stahlmann-Brown ${ }^{1} \cdot$ P. Walsh ${ }^{2}$
}

Received: 9 March 2021 / Accepted: 29 January 2022 / Published online: 1 March 2022

(c) The Author(s) 2022

\begin{abstract}
The literature on belief regarding climate is extensive, with results showing that both personal characteristics and personal experience with the effects of climate change strongly influence future expectations. The vast majority of studies rely on cross-sectional data, making it difficult to ascertain the durability of expectations regarding future climate or the effect of additional environmental cues on beliefs. A few panel studies of which we are aware exploit extreme weather events to find evidence of "confirmation bias", in which additional environmental signalling reinforces existing beliefs. In contrast, we evaluate how normal fluctuations in soil moisture causally impact expectations of future drought using a panel of New Zealand farmers. We find that environmental cues such as soil moisture scarcely affect expectations of respondents who already expected future drought to increase but that soil moisture strongly influences respondents who did not. In particular, drier soils are associated with higher expectations of future drought among these former sceptics, whether they previously believed that future drought would decrease or simply would not change. Thus, as New Zealand moves toward IPCC forecasts of more frequent and more severe drought, farmers, foresters, and growers will increasingly agree with the scientific consensus, raising the likelihood of both farm-level and public action.
\end{abstract}

Keywords Drought $\cdot$ Climate change $\cdot$ Beliefs $\cdot$ Updating $\cdot$ Survey of Rural Decision Makers

\section{Introduction}

Expectations regarding future climate drive private adaptation and mitigation (Arbuckle et al. 2013; Vainino and Paloniemi 2013) as well as support for public action (Bernauer 2013; Stehr 2015; Drews and Van den Bergh 2016). These expectations are rooted in personal characteristics and social identity (Hornsey et al. 2016), but personal experience also strongly influences belief (Borick and Rabe 2010; Deryugina 2013; Demski et al. 2017). In

P. Stahlmann-Brown

brownp@landcareresearch.co.nz

1 Manaaki Whenua - Landcare Research, Wellington, New Zealand

2 Manaaki Whenua - Landcare Research, Auckland, New Zealand \& US Environmental Protection Agency, DC, Washington, USA 
this paper, we use panel data from a national survey of thousands of farmers and other rural decision makers to analyse belief updating in the context of fluctuations in soil moisture, an important indicator for farm planning, over a 2-year period. More specifically, we estimate the effects of variation in soil moisture on expectations regarding future drought.

If respondents change from one set of expectations to another based on differences in soil moisture, then we infer that signalling results in belief change, a result that would be consistent with cross-sectional studies that have found that personal experience with weather and proximal environmental cues is associated with belief in climate change. This result has been demonstrated for significant natural disasters such as flooding (Spence et al. 2011), cyclones (Brown et al. 2017), and drought (Diggs 1991; Booth et al. 2020) as well as variability in temperature ( $\mathrm{Li}$ et al. 2016; Brooks et al. 2014; Zaval et al. 2014) and rainfall (Taylor et al. 2014), particularly when unexpected variation persists (Egan and Mullin 2012). The underlying inference of these studies is that personal experience makes climate change feel more relevant and immediate to survey respondents, increasing the likelihood that they become concerned (Weber 2006; Ackerlof et al. 2013).

In contrast, if additional signalling does not cause survey respondents to update beliefs, then our findings would echo those of Whitemarch (2008), who shows that US flood victims are indistinguishable in their beliefs about climate change from individuals who did not experience flooding. One potential explanation is so-called confirmation bias (Rabin and Schrag 1999) or motivated reasoning (Myers et al. 2013; Bénabou and Tirole 2016), in which new information is filtered and processed in a manner that confirms prior beliefs and attitudes (Lord et al. 1979; Hahn and Harris 2014). An alternative potential explanation emerges if people update beliefs related to changing climate primarily in response to catastrophic natural disasters (Konisky et al. 2016) rather than more muted environmental cues.

We focus on personal experience rather than information provided by others because personal experience has a greater influence on belief formation than information from outside sources, even close relations (Hertwig et al. 2004). This may be because people overvalue their own experience in risk assessments and discount others (Van Boven and Lowenstein 2005). Alternatively, some risks might vary sufficiently across individuals and space that others' experiences are considered less valid (Viscusi and Zeckhauser 2015). Indeed, when the facts about a risk are in dispute, the role of personal experience plays an even larger role in belief formation (Van Boven and Lowenstein 2005).

We measure personal experience using objective measures of soil moisture recorded at 76 weather stations located throughout New Zealand. Moreover, our survey sample is entirely comprised of farmers, foresters, and growers, for whom even small fluctuations in soil moisture are both recognisable and meaningful. Most importantly, we use panel survey data, enabling us to infer the direct, causal effect of signalling on expectations regarding future drought, alleviating concerns that climate change beliefs influence interpretation of extreme events rather than the converse (Goebbert et al. 2012; Myers et al 2013) while controlling for timeinvariant personal characteristics of survey respondents. In addition, some parts of the country were considerably drier at the time of the second survey relative to the first survey while others were significantly wetter, allowing us to evaluate marginal changes in the treatment.

We are aware of only a small handful of studies that exploit panel data to analyse climate change beliefs using empirical measures of experience rather than self-reported experience. Among these, Carlton et al. (2016) find just a 0.8 percentage point increase in the share of agricultural advisors who report believing in climate change following the worst drought in the US Midwest in 25 years. Palm et al. (2017) find that variability in January weather was associated with greater scepticism among climate change sceptics and greater belief among climate change believers while neither July temperatures, drought, fatalities 
and injuries from natural disasters, or crop and property damage from natural disasters had any effect on belief among panel survey respondents in the USA. Finally, Osberghaus and Fugger (2019) analyse panel survey data administered both before and after one of the largest floods to affect Germany in decades; they find that within the subsample of climatechange believers before the flood, exposure to flooding increased the propensity to retain their pre-treatment belief in climate change; similarly, within the subsample of climatesceptical respondents, those who were affected by flooding were more likely to retain their sceptical beliefs compared to unaffected individuals. All of these results are broadly consistent with confirmation bias, in which new information reinforces previously held expectations regarding climate. ${ }^{1}$

In contrast, we find that new signalling in the form of more intensive drought is associated with increased expectations regarding future drought, especially among those who did not previously expect drought to increase. New signals - whether in the form of wetter or drier soils - have little bearing on the future expectation of those who already expected drought to increase.

In the next section of the paper, we provide an overview of the survey microdata, our measure of soil moisture, and the empirical approach. Results and a conclusion follow.

\section{Methods}

\subsection{Survey of Rural Decision Makers}

Conducted biennially since 2013, the Survey of Rural Decision Makers collects detailed information on issues of topical interest to primary industry in New Zealand. Questions pertaining to climate and future expectations have been included since 2015 .

The sample was initially drawn from official databases, and subsequent waves have been widely promoted by industry bodies and central and regional government. Respondents represent the entirety of primary industry in all 66 districts comprising mainland New Zealand, although the dairy and sheep and beef industries are overrepresented as an artefact of the sampling strategy.

The 2017 wave was open from September until November 2017, yielding 4458 complete responses (Brown 2017). The 2019 wave was open from July until November 2019, yielding 3740 complete responses (Brown 2019). In total, 1540 individual respondents answered questions pertaining to future climate in both the 2017 and 2019 waves of the survey.

Table 1 (panel A) provides summary statistics for our matched sample as of 2017. The median respondent is a 58-year-old white male whose family has been farming in New Zealand for two generations. He has 24 years of experience in primary industry but does not have a tertiary education. These demographic traits are broadly similar to those for non-panel respondents to the Survey of Rural Decision Makers (Brown et al. 2019) and to the New Zealand farming and forestry sector as a whole (Statistics New Zealand 2012). Like other time-invariant individual-level characteristics, these demographic factors are controlled for in our panel data estimates.

\footnotetext{
${ }^{1}$ Myers et al. (2013) similarly find evidence of confirmation bias using panel data with self-reported measures of experience with climate change.
} 


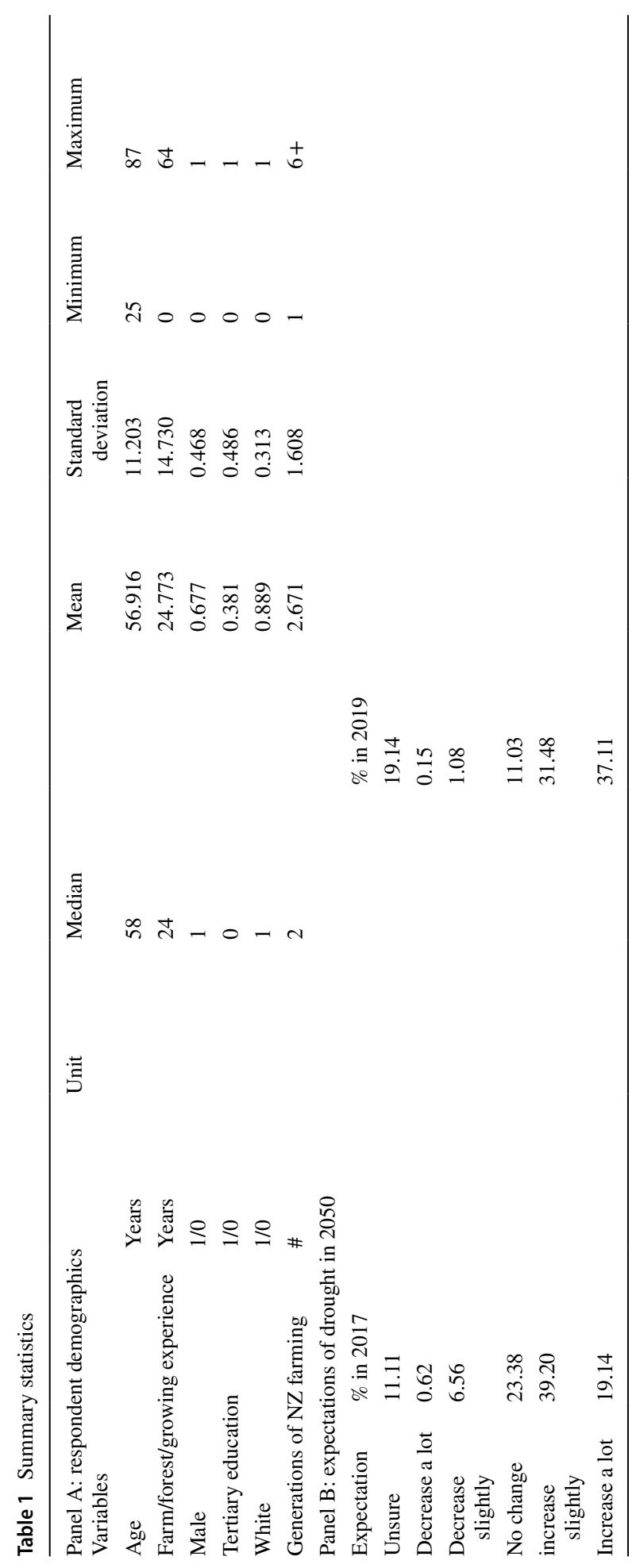


Perceptions of drought in New Zealand in the year 2050 were measured slightly differently in 2017 and 2019. In 2017, respondents were asked "How do you personally expect the prevalence of drought in [your district] to change by 2050?" Respondents chose from the following answers: decrease a lot, decrease somewhat, no change, increase somewhat, increase a lot, and unsure. In 2019, the questionnaire followed the structure proposed by Eval-MAP (Osberghaus and Demski 2019), such that respondents were first asked "Which of the following statements best describes your personal thoughts about climate change?" Respondents chose from the following answers: climate change is already affecting New Zealand; although climate change is not yet affecting New Zealand, it will in the next 10 years; although climate change will not affect New Zealand in the next 10 years, it will in the future; climate change will not affect New Zealand; and unsure. ${ }^{2}$ Respondents who indicated that climate change is already affecting or will affect New Zealand in the future were then asked "Will climate change affect the frequency or intensity of drought in your district by 2050 ?" Responses included yes, no, and unsure. Finally, respondents who selected yes were asked "How do you personally expect the frequency and intensity of drought in your district to change by 2050?" Respondents chose from the following answers: decrease a lot, decrease somewhat, no change, increase somewhat, increase a lot, and unsure.

Panel B shows summary statistics expectations regarding future drought as answered in 2017 and 2019. Given the structure of the questions and the implicit linking of drought to climate change in 2019 , it is perhaps not surprising that more respondents are coded as being unsure about future drought in the 2019 wave than in the 2017 wave of the survey. Comparing the distributions between years, much of the movement to "unsure" derives from those who stated that drought would decrease in 2017.

Regardless, expectations that drought would increase in the future also increased over the 2-year period. This shift is consistent with increasing belief in climate change among New Zealanders (e.g. Milfont et al. 2017). It may also stem from general awareness of climate change and climatic issues resulting from global climate strikes in March, May, and September 2019, each of which drew tens of thousands of participants and significant media attention in New Zealand. Similarly, the establishment of the New Zealand Climate Commission raised the profile of climate change in New Zealand.

\subsection{New Zealand Drought Index}

With approximately 55,000 farm and forestry holdings, agriculture is a dominant sector and an important contributor to the New Zealand economy, accounting for approximately two thirds of exports by value (StatsNZ 2017). Drought is not uncommon in many parts of the country, and severe and prolonged drought can significantly reduce agricultural production, affect animal health, disrupt rural industry, and result in hardship to rural residents (Mol et al. 2017; Pourzand and Noy 2018). Mishra and Singh (2010) further observe that drought contributes to soil erosion and greater susceptibility of plant disease and wilting. For instance, the 2013 drought is conservatively estimated to have caused GDP to fall by $0.6 \%$ and to have spurred a $3 \%$ decline in the exchange rate (Kamber et al. 2013). Drought is thus a highly salient component of climate change for New Zealand's rural sector.

\footnotetext{
${ }^{2}$ See also http://www.rwi-essen.de/forschung-und-beratung/umwelt-und-ressourcen/projekte/eval-map/.
} 
Atmospheric projections based on simulations undertaken for the IPCC Fifth Assessment Report indicate that drought in New Zealand will increase in both severity and frequency (MfE 2018), with time spent in drought in parts of the country doubling or even tripling by 2040 (New Zealand Climate Centre 2014). While farmers, foresters, and growers are highly attuned to rainfall and water retention of soil (Slegers 2008), self-reported experience of drought could be biased by personal characteristics of the respondent, strategic or stochastic recall error (Hassan 2005; Chen et al. 2017), or media coverage of weather (Wahlquist 2003). Hence, we use empirical measures of water availability in our analysis.

The New Zealand Drought Index (NZDI) is calculated from four existing indices, the Standardised Precipitation Index, Soil Moisture Deficit and its anomaly, and the Potential Evapotranspiration Deficit, chosen due to sensitivity to rainfall and soil moisture, data availability across time and space, interpretability, and balance of absolute and relative indices (Mol et al. 2017). ${ }^{3}$ These indices are measured at weather stations across New Zealand, 76 of which are close to population centres and are thus used in our analysis.

To form the NZDI, these indices are combined into one overall index ranging from 0 to 2. The New Zealand Institute for Water and Atmospheric Research applies five numeric thresholds in order to categorise soil moisture availability (NIWA 2019a):

- $\geq 0.75$ dry;

- $\geq 1.00$ very dry;

- $\geq 1.25$ extremely dry;

- $\geq 1.50$ drought; and

- $\geq 1.75$ severe drought.

These categories help inform government decisions about funding recovery measures for medium-scale and large-scale events.

Given the panel nature of the data, our analysis focuses on differences in the NZDI between 2017 and 2019. Because New Zealand farmers are disproportionately impacted by soil moisture deficits during summer and autumn (Booth et al. 2020), we consider water availability during these months.

\subsection{Estimation procedure}

In a meta-analysis of related papers, Hornsey et al. (2016) find that values, ideology, world view, political orientation, and demographic variables predict belief in climate change. Similarly, Brulle et al. (2012) and Carmichael and Brulle (2017) note that political identity and structural economic factors have larger impacts on perceptions of climate change than science. As such, studies reliant on cross-sectional data may attempt to include variables to control for such measures when analysing the effect of exposure to weather and other proximal environmental cues on beliefs. Failure to control for any such characteristic in cross-sectional studies leads to omitted variable bias, which makes estimated coefficients on climate signals difficult to interpret.

\footnotetext{
${ }^{3}$ Other potential measures include the Palmer Drought Severity Index and the Standardised PrecipitationEvapotranspiration Index.
} 
In this study, we control for all time-invariant personal characteristics by exploiting panel data to examine whether new climate signals trigger belief updating. ${ }^{4}$ Specially, we employ logistic regression in which expectations of future drought as reported in 2019 are regressed on expectations of future drought as reported in 2017 and its interaction with soil moisture. That is as follows:

$$
y_{i j 19}=\beta_{0}+\beta_{1} y_{i j 17}+\beta_{2} \Delta N Z D I_{j}+\gamma\left(y_{i j 17} \times \Delta N Z D I_{j}\right)+\epsilon_{i j}
$$

where $y_{i j 19}$ is a binary variable indicating whether respondent $i$ living in proximity to weather station $j$ believes that drought in his or her area will increase somewhat or increase a lot by the year 2050 as of 2019 .

$$
y_{i j 19}=\left\{\begin{array}{c}
1 \text { if the respondents believes that drought will increase } \\
0 \text { if the respondent does not believe that drought will increase }
\end{array}\right.
$$

with $\operatorname{Pr}\left(y_{i j 19}=1\right)=F\left(\beta_{0}+\beta_{1} y_{i j 17}+\beta_{2} \Delta N Z D I_{j}+\gamma\left(y_{i j 17} \times \Delta N Z D I_{j}\right)\right)+e_{i j}, \quad$ where $F()$ is the logistic function. $y_{i j 17}$ is an indicator variable for whether the same respondent believed that drought would either increase somewhat or increase a lot by the year 2050 as of 2017. $\triangle N Z D I_{j}$ is the change in the NZDI at weather station $j$ between 2017 and 2019; $\triangle N Z D I_{j}$ is measured both linearly and as a count indicating the number of soil moisture thresholds crossed as explained in the previous section. We measure the change in soil moisture availability as the difference in the maximum monthly NZDI recorded at weather station $j$ between January and June 2017 and between January and June 2019, although we also consider alternative measures in our robustness checks. $e$ is a heteroskedasticity-robust standard error, and we assume that $e \sim N\left(0, \sigma^{2}\right)$.

To test whether other categories of drought expectations are important (as opposed to drought will increase vis-à-vis drought will not increase), we also implement an ordered logit framework as follows:

$$
\operatorname{Pr}\left(y_{i j 19}=w\right)=\operatorname{Pr}\left(k_{w-1} \leq \beta_{0}+\beta_{1} y_{i j 17}+\beta_{3} \Delta \mathrm{NZDI}_{j}+\gamma\left(y_{i j 17} \times \Delta \mathrm{NZDI}_{j}\right)+\epsilon_{i j} \leq k_{w}\right)
$$

where $k_{0}=-\infty, k_{w}=\infty$ and $w$ index expectations to the full set of possible expectations regarding drought in 2050 , i.e. decrease, no change, and increase.

Since they control for characteristics that do not change over time, these panel methods allow us to infer the causal impact of personally experienced drought signals on drought expectations.

\section{Results}

Table 2 (panel A) shows the transition matrix from expectations in 2017 to expectations in 2019 for all respondents. While $86.3 \%$ respondents who expected future drought to increase as of 2017 continued to believe that it will increase as of 2019, a minority downgraded

\footnotetext{
${ }^{4}$ Panel methods will not address omitted variable bias stemming from time-variant personal-level characteristics (Cunningham 2021); hence, our models assume that values, ideology, political orientation, etc. are static over the two-year study period. While we do not expect personal characteristics such as values, world view, or political orientation to have changed between the two waves of the survey, we acknowledge that the possibility exists.
} 

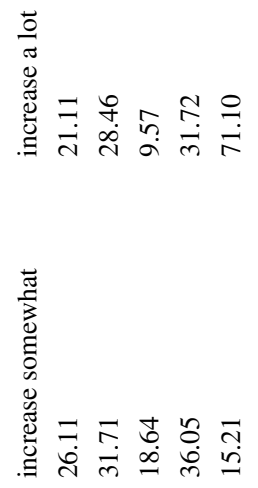

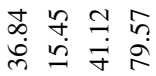

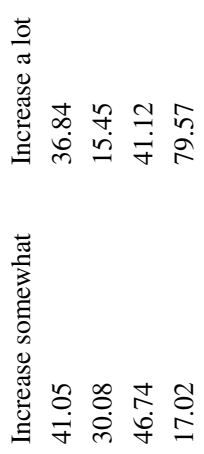

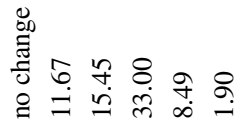

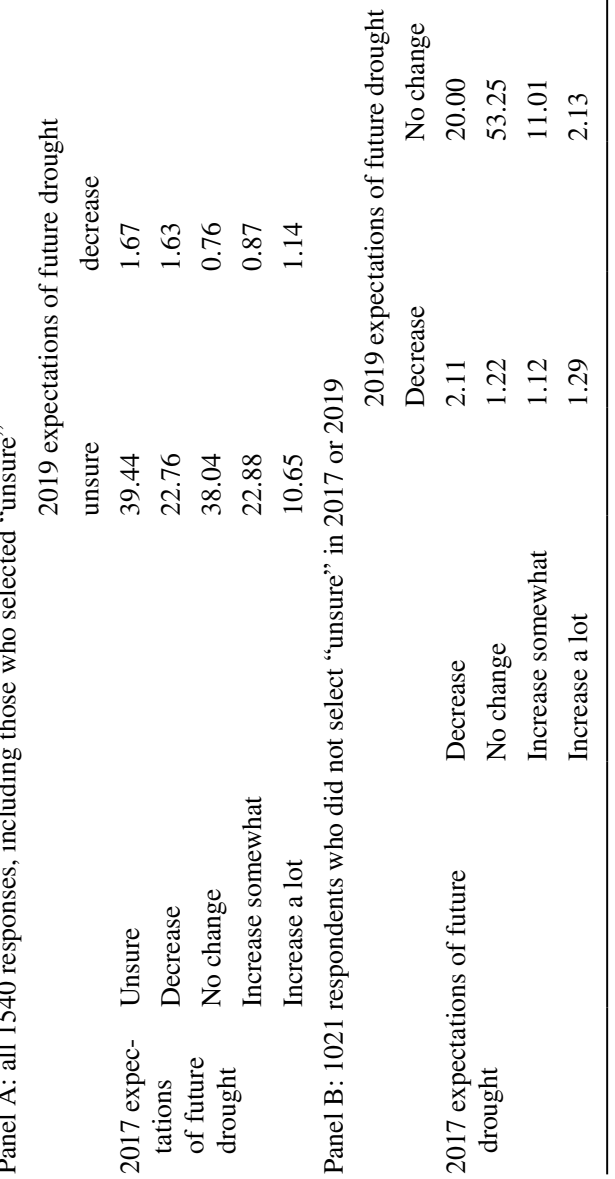


Table 3 Transition Matrix in the New Zealand Drought Index between 2017 and 2017 for 76 weather stations

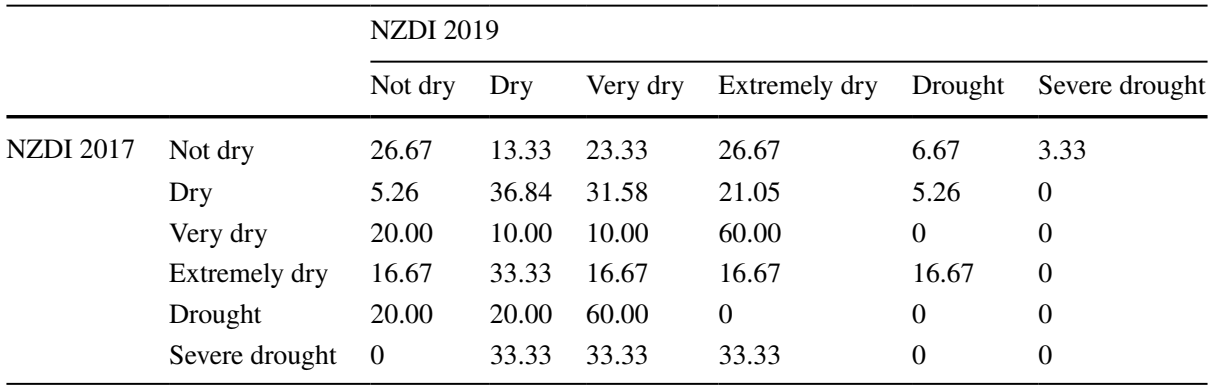

NZDI is measured as the maximum monthly NZDI measured between January and June of each year

their assessments to uncertainty, no change, and even decrease. Those who expected future drought to be unchanged as of 2017 were most likely to report being unsure, to expect drought to remain unchanged, or to increase as of 2019. And, notably, only $1.6 \%$ of survey respondents who expected future drought to decrease as of 2017 continued to expect it to decrease as of 2019. Instead, $60.2 \%$ of these respondents report believing that future drought will increase as of 2019. Among respondents who were unsure about future drought as of $2017,47.2 \%$ reports believing that drought will increase as of 2019 . That is, while some uncertainties about future drought persist between 2017 and 2019, more individuals across all response groups ultimately believe that drought will increase.

Being "unsure" about future drought may reflect true ambiguity, but it may also be a product of question complexity and coding. Thus, panel B presents a new transition matrix for the 1021 respondents who expressed no uncertainty about future drought in either wave of the survey. Our subsequent analysis will focus on this group of respondents, although we return to the "unsure" responses in our robustness checks. While $79.6 \%$ of respondents who believe that drought will increase a lot as of 2017 hold the same belief as of 2019, only $2.1 \%$ of those who believe that drought will decrease as of 2017 continue to believe so as of 2019. Indeed, the "decrease" expectation exhibits much greater mobility than any other expectation. More respondents therefore align their expectations with scientific projections of future drought during the study period.

The "Introduction" provides many examples of extreme weather and other environmental signals correlating with belief in climate change, so a widespread drought could foreseeably produce the transitions described in the previous paragraph. However, while 11 of the 76 weather stations included in our analysis had NZDIs that met the thresholds for "drought" or "severe drought" in 2017, only five did in 2019. One weather station that did not meet the "dry" threshold in 2017 met the threshold for "extreme drought" in 2019, and two met the threshold for "drought" in 2019. Indeed, while some areas were drier in 2019 than in 2017, many others were wetter. As such, neither summer-autumn 2017 nor summer-autumn 2019 was remarkable in terms of drought, so rather than focusing on extreme events, our analysis emphasises marginal changes in soil moisture that are nevertheless recognisable and meaningful to our study population. A full transition matrix in NZDI for the 76 weather stations is presented in Table 3.

From the logistic regression described in Eq. 1, we calculate the following odds ratios: $\beta_{1}=8.85(p<0.01), \beta_{2}=2.23$ for those who did not expect future drought to increase as of 
Table 4 Predicted probabilities that respondents expect drought to increase in the future as of 2019 as a function of 2017 expectations and change in the New Zealand Drought Index, measured as a continuous variable

\begin{tabular}{|c|c|c|}
\hline \multirow[b]{2}{*}{$\begin{array}{l}\text { Continuous change in } \\
\text { NZDI } 2017 \text { to } 2019\end{array}$} & \multicolumn{2}{|l|}{ Predicted probabilities } \\
\hline & $\begin{array}{l}\text { 2017: drought will not } \\
\text { increase in the future }\end{array}$ & $\begin{array}{l}\text { 2017: drought will } \\
\text { increase in the future }\end{array}$ \\
\hline \multirow[t]{2}{*}{-1.14 (wetter) } & $0.309 * * *$ & $0.843 * * *$ \\
\hline & $(0.0672)$ & $(0.0462)$ \\
\hline \multirow[t]{2}{*}{-0.63 (wetter) } & $0.402 * * *$ & $0.876^{* * * *}$ \\
\hline & $(0.0490)$ & $(0.0240)$ \\
\hline \multirow[t]{2}{*}{-0.12 (wetter) } & $0.503 * * *$ & $0.903 * * *$ \\
\hline & $(0.0302)$ & $(0.0120)$ \\
\hline \multirow[t]{2}{*}{+0.38 (drier) } & $0.604 * * *$ & $0.924 * * *$ \\
\hline & $(0.0322)$ & $(0.0126)$ \\
\hline \multirow[t]{2}{*}{+0.89 (drier) } & $0.696 * * *$ & $0.941 * * *$ \\
\hline & $(0.0483)$ & $(0.0166)$ \\
\hline \multirow[t]{2}{*}{+1.40 (drier) } & $0.775^{* * * *}$ & $0.954 * * *$ \\
\hline & $(0.0595)$ & $(0.0190)$ \\
\hline Observations & 1,021 & \\
\hline
\end{tabular}

Separate columns based on 2017 expectations are presented to aid interpretation; the sample was not split in the regression. NZDI is measured as the maximum monthly NZDI between January and June of each year. Heteroskedasticity-robust standard errors are shown in parentheses. $* * * p<0.01, * * p<0.05, * p<0.1$

2017 ( $p<0.01$ ), and $\beta_{2}+\gamma=1.71$ for those who did expect future drought to increase as of $2017(p<0.10)$. That is, changes in soil moisture are associated with strong belief updating among those who previously reported that they did not expect future drought to increase.

Full regression results are available in Table 7 (column 1). To facilitate interpretation, we plot predicted probabilities corresponding to the belief that drought will increase in the future for changes in the NZDI based on the logistic estimates (Table 4). Results are presented in separate columns for those who did not/did believe that drought would increase in the future as of 2017, although the sample was not split in the regression. Predicted probabilities monotonically increase with soil dryness and range from 0.31 to 0.78 for respondents who did not expect future drought to increase as of 2017 and from 0.84 to 0.95 for respondents who did expect future drought to increase as of 2017. That is, drought sceptics are more likely to change their minds based on new signalling while soil moisture has only a modest impact on the expectations of respondents who already thought that drought would increase. These results are presented graphically in Fig. 1.5

NIWA (2019a)'s NZDI thresholds inform government decisions regarding drought recovery (MPI 2019). Assuming that such thresholds also convey meaning to farmers, foresters, and

\footnotetext{
${ }^{5}$ One possible explanation for the finding that soil moisture has modest signalling value for respondents who already believed that drought would increase as of the first wave of the survey is the so-called ceiling effect (Austin and Brunner 2003), whereby variance in a dependent variable Is not measured above a certain level and thus regressors have no explanatory power. However, we do not believe that this explains our findings. First, the predicted probability is strictly less than 1 across the full range of soil moisture measures. Second, our slope variable $\left(\$ \$\{\text { beta }\}_{-}\{2\}+\right.$ Igamma $\$$ ) is statistically significant in our estimates.
} 
Table 5 Predicted probabilities that respondents expect drought to increase in the future as of 2019 as a function of 2017 expectations and change in the New Zealand Drought Index, measured in the number of soil moisture thresholds crossed

\begin{tabular}{llc}
\hline \multirow{2}{*}{$\begin{array}{l}\text { Change in NZDI } 2017 \text { to } 2019, \text { measured as } \\
\text { thresholds crossed }\end{array}$} & $\begin{array}{l}\text { Predicted probabilities } \\
\text { the future }\end{array}$ & $\begin{array}{c}2017: \text { drought will not increase in } \\
\text { 2017: drought will } \\
\text { increase in the future }\end{array}$ \\
\hline 3/4/5 thresholds wetter & $0.308^{* *}$ & $0.846^{* * *}$ \\
& $(0.128)$ & $(0.0708)$ \\
2 thresholds wetter & $0.471^{* * *}$ & $0.892^{* * *}$ \\
& $(0.0542)$ & $(0.0255)$ \\
1 threshold wetter & $0.400^{* * *}$ & $0.860^{* * *}$ \\
& $(0.127)$ & $(0.0491)$ \\
No change & $0.500^{* * *}$ & $0.916^{* * *}$ \\
& $(0.0694)$ & $(0.0242)$ \\
1 threshold dryer & $0.513 * * *$ & $0.930^{* * *}$ \\
2 thresholds dryer & $(0.0574)$ & $(0.0195)$ \\
& $0.682^{* * *}$ & $0.889 * * *$ \\
$3 / 4 / 5$ thresholds drier & $(0.0574)$ & $(0.0316)$ \\
Observations & $0.758^{* * *}$ & $0.982^{* * *}$
\end{tabular}

Separate columns based on 2017 expectations are presented to aid interpretation; the sample was not split in the regression. NZDI is measured as the maximum monthly NZDI between January and June of each year. NIWA (2019a) explains these thresholds in detail. Heteroskedasticity-robust standard errors are shown in parentheses. $* * * p<0.01, * * p<0.05, * p<0.1$

growers, we replace our continuous measure of change in NZDI in Eq. 1 with a categorical measure, which places less restriction on the functional form. Table 5 presents predicted probabilities that respondents believe that drought will increase based on previous expectations and the number of soil-moisture thresholds crossed (full results are presented in Table 7 (column 2)). While the predicted probabilities no longer rise monotonically with soil dryness, wetter conditions are associated with lower expectations regarding future drought and drier conditions are associated with higher expectations. Probabilities range from 0.31 to 0.76 for respondents who did not expect future drought to increase as of 2017 and from 0.85 to 0.98 for respondents who did expect future drought to increase as of 2017. These results are presented graphically in Fig. 2.

Finally, we disaggregate expectations regarding future drought from two categories (drought will increase and drought will not increase) to three categories (drought will decrease, drought will not change, drought will increase), ${ }^{6}$ employing an ordered

\footnotetext{
${ }^{6}$ To simplify the presentation of results, we do not distinguish between "decrease somewhat" and "decrease a lot" or between "increase somewhat" and "increase a lot" in this analysis. A full of results is available from the authors.
} 
Table 6 Predicted probabilities for each expectation of future drought as of 2019 as a function of 2017 expectations and change in the New Zealand Drought Index, measured as a continuous variable

Panel A: 2017: drought will decrease in the future

Continuous change in NZDI 2017 to 2019

-1.00 (wetter)

$\begin{array}{lll}\text { Decrease } & \text { No change } & \text { Increase } \\ 0.0129 & 0.264 * * & 0.723 * * * \\ (0.0103) & (0.135) & (0.144) \\ 0.0104 * * & 0.225 * * * & 0.765 * * * \\ (0.00444) & (0.0482) & (0.0513) \\ 0.00836 * & 0.190 * * * & 0.802 * * * \\ (0.00458) & (0.0725) & (0.0763)\end{array}$

Panel B: 2017: drought will not change in the future

Continuous change in NZDI 2017 to 2019

-1.00 (wetter)

Decrease

$0.0694 * * *$

No change

Increase

(0.0220)

$0.617 * * *$

$0.314 * * *$

$+0.00$

$0.0376^{* * * *}$

(0.0530)

(0.0620)

(0.0100)

$0.497 * * *$

$0.466^{* * * *}$

+1.00 (drier)

$0.0201 * *$

(0.0323)

(0.0309)

(0.00811)

$0.356 * * *$

$0.624 * * *$

Panel C: 2017: drought will increase in the future

Continuous change in NZDI 2017 to 2019

-1.00 (wetter)

Decrease

(0.0612)

(0.0665)

$$
\begin{aligned}
& +0.00 \\
& +1.00 \text { (drier) }
\end{aligned}
$$$$
0.00586 * *
$$$$
(0.00254)
$$$$
0.00346^{* * * *}
$$$$
\text { (0.00122) }
$$

$0.00204 * *$

(0.000973)

1,021

$\begin{array}{ll}\text { No change } & \text { Increase } \\ 0.142 * * * & 0.852 * * * \\ (0.0375) & (0.0393) \\ 0.0891 * * * & 0.907 * * * \\ (0.0107) & (0.0113) \\ 0.0546 * * * & 0.943 * * * \\ (0.0168) & (0.0176)\end{array}$

Observations

NZDI is measured as the maximum monthly NZDI between January and June of each year. Heteroskedasticity-robust standard errors are shown in parentheses. $* * * p<0.01, * * p<0.05, * p<0.1$

logit model per Eq. 2. Table 6 shows the predicted probabilities from that regression, with each panel corresponding to a different response in 2017. Columns correspond to the predicted probability for 2019 beliefs. For example, predicted probabilities among respondents who believed that future drought will decrease as of 2017 are presented in panel A. This group overwhelming updates their beliefs regardless of soil moisture, with a predicted probability of believing that drought will increase in the future of 0.72 even when the 2019 NZDI is 1.00 wetter than the 2017 NZDI $(p<0.01)$. Panel C shows predicted probabilities for respondents who believed that drought would increase as of 2017. For this group, the predicted probability of expecting drought to increase exceeds 0.85 across the range of soil moisture measures. In contrast, respondents who expected no change in drought as of 2017 (panel B) are much more likely to maintain those beliefs in 2019, especially if soil moisture is wetter in 2019 than in 2017. As soils turn drier, however, this group increasingly expects future drought to increase. Overall, these results indicate that environmental signalling in the form of soil moisture has little 


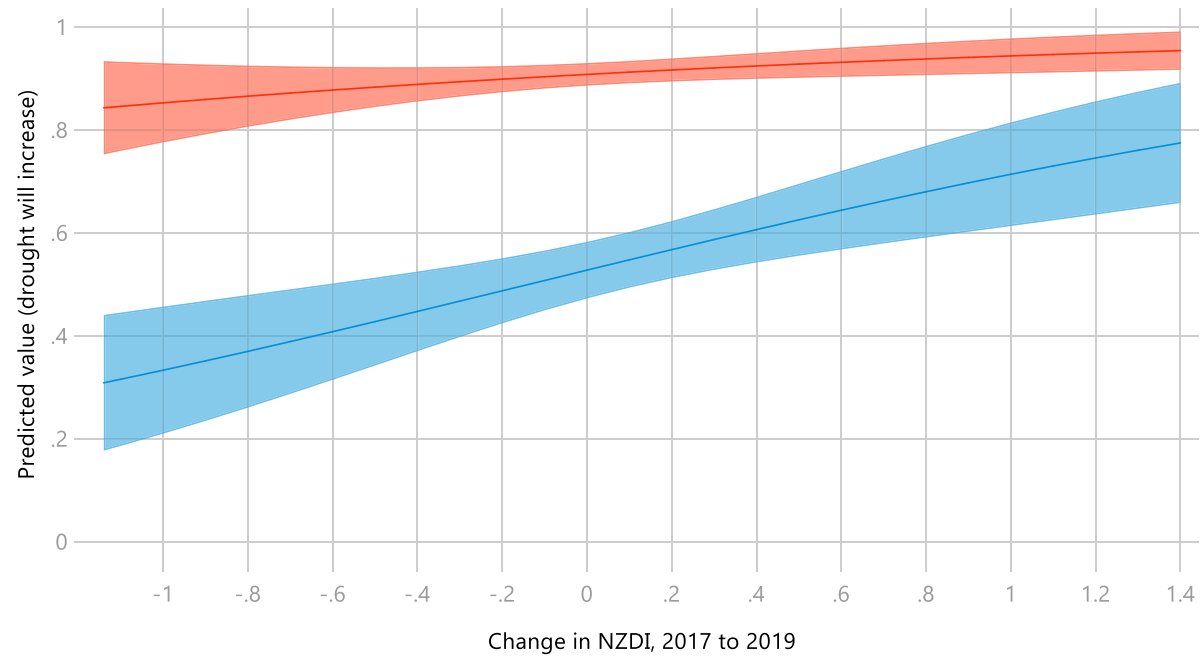

Change in NZDI, 2017 to 2019

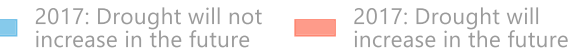

Fig. 1 Predicted probabilities that respondents expect drought to increase in the future as of 2019 as a function of 2017 expectations and change in the New Zealand Drought Index, measured as a continuous variable

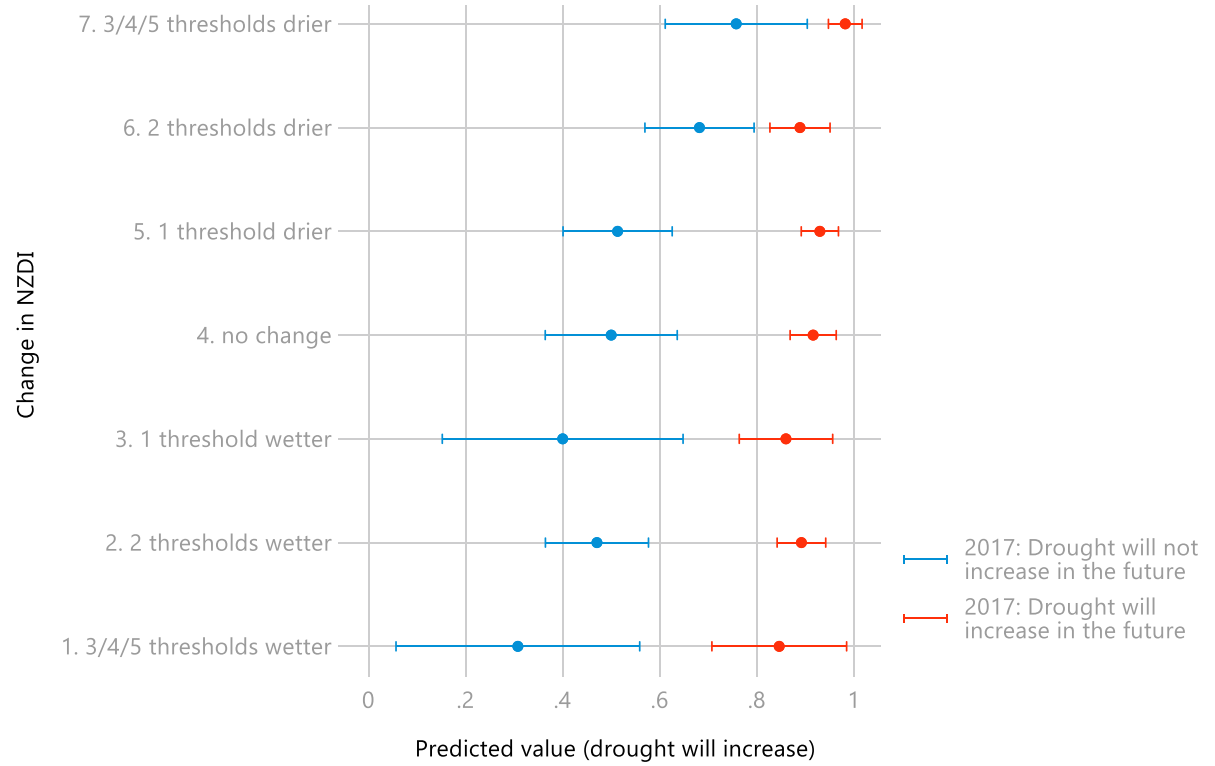

Fig. 2 Predicted probabilities that respondents expect drought to increase in the future as of 2019 as a function of 2017 expectations and change in the New Zealand Drought Index, measured in thresholds crossed 

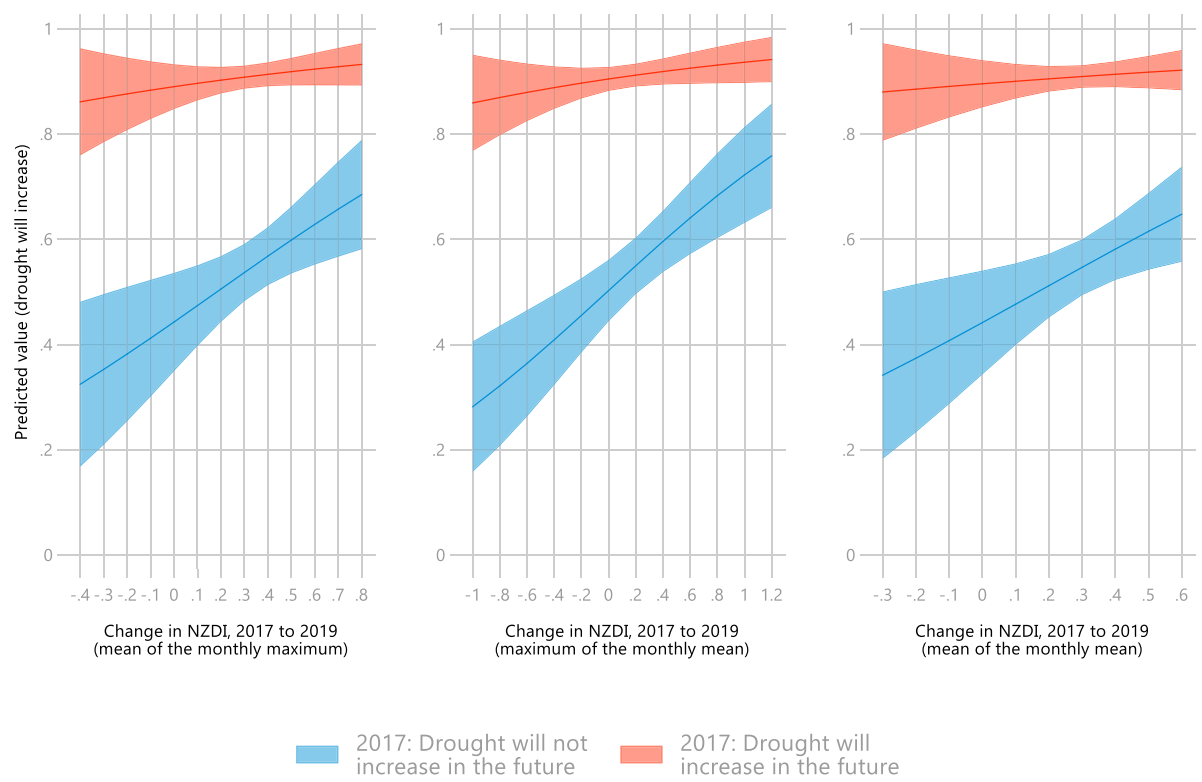

Fig. 3 Predicted probabilities that respondents expect drought to increase in the future as of 2019 as a function of 2017 expectations and alternative measures of change in the New Zealand Drought Index

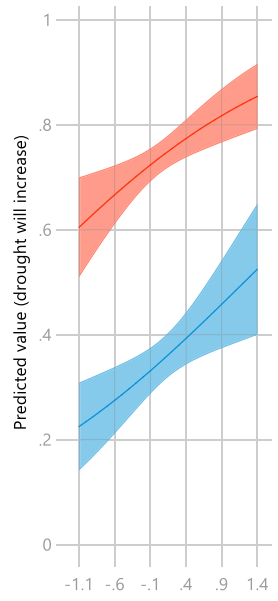

Change in NZDI, 2017 to 2019 (max of the monthly max)

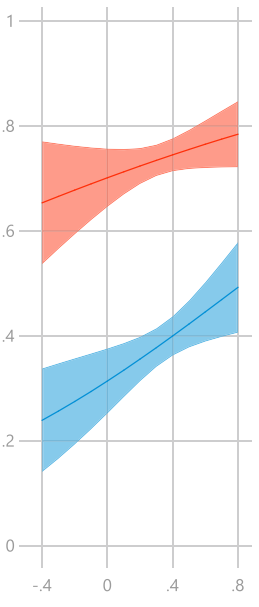

Change in NZDI, 2017 to 2019 (mean of the monthly max)

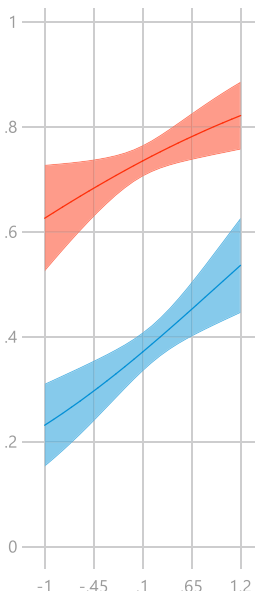

Change in NZDI, 2017 to 2019 (max of the monthly mean)

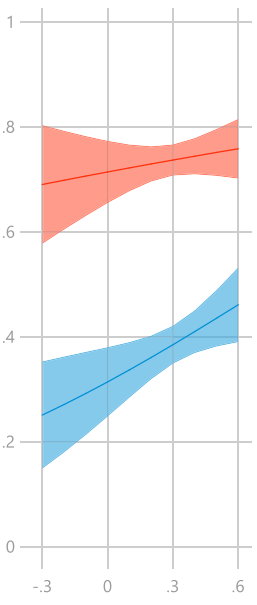

Change in NZDI, 2017 to 2019 (mean of the monthly mean)

$$
\begin{aligned}
& \text { 2017: Drought will not } \square \text { 2017: Drought will } \\
& \text { increase in the future } \quad \square \text { in the future }
\end{aligned}
$$

Fig. 4 Predicted probabilities that respondents expect drought to increase in the future as of 2019 as a function of 2017 expectations for all measures of change in the New Zealand Drought Index, including "unsure" responses 
effect on those who already believed that future drought would increase or decrease as of 2017, but this environmental cue strongly influences expectations among those who expected no change in future drought as of 2017. Full model estimates are reported in Table 8.

\subsection{Robustness}

In all results described above, the change in soil moisture at any weather station is measured as the difference in the maximum monthly NZDI between January and June. Alternative measures that could have been selected include the mean of the monthly maximum NZDI, the maximum of the monthly mean NZDI, and the mean of the monthly mean NZDI. Hence, we re-estimate Eq. 1 and present the predicted probabilities of expecting that drought will increase in the future in Fig. 3. Ultimately, the measure chosen does not impact the main results: respondents who did not believe that future drought would increase as of 2017 are much more influenced by additional environmental signalling than respondents who believed that future drought would increase as of 2017 regardless of how change in the NZDI is measured.

As a final robustness check, we reintroduce respondents who indicated uncertainty about future drought in either the 2017 or 2019 wave of the survey; specifically, we re-estimate Eq. 1 with these responses categorised as "drought will not increase in the future" for all four measures of $\triangle N Z D I$. As above, soil dryness strongly influences the expectations of respondents who did not previously expect future drought to increase (Fig. 4). For example, using change in the mean of the monthly means as out measure of changed NZDI, the predicted probability of expecting drought to increase in the future ranges from 0.25 when the NZDI is -0.3 to 0.46 when the NZDI is +0.6. Among respondents who did previously expect future drought to increase, the predicted probabilities range from 0.69 to 0.76 . With the previously omitted "unsure" responses included in the sample, environmental signalling has only a slightly weaker effect for those who expected drought to increase as of 2017 than for the who did not using change in the maximum of the monthly maximum, the conservative measure we chose for the main analysis.

\section{Conclusion}

To properly adapt to the future impacts of climate change, current land-use planning decisions should incorporate the best available data. Personal beliefs about risk can influence planning decisions, so it is important to explore how these beliefs change. Furthermore, since governments provide risk information through channels as varied as drinking water advisories, weather forecasts, and contamination warnings, it is vital to explore the role of personal experience in forming risk beliefs (Viscusi and Zeckhauser, 2015).

Several factors unrelated to environmental conditions (such as personal characteristics and social identity) have been demonstrated to affect future expectations and hence 
planning decisions (e.g. Brulle et al. 2012; Hornsey et al. 2016). Other recent research has focussed on whether personal experience with weather events and proximal environmental cues of climate change can affect beliefs independent of personal characteristics and social identity. However, panel studies of future expectations regarding climate are rare, and thus most studies are unable to fully account for personal characteristics and social identity.

In this paper, we exploit natural variation in soil moisture to analyse environmental cues on future expectations using panel data to control for time-invariant personal characteristics. Soil moisture is well understood by our survey sample of farmers, foresters, and growers and is highly relevant for land-use planning. We find that even modest increases in soil dryness can shift future expectations, and these results are robust to a variety of specifications.

Moreover, signalling in the form of soil moisture matters particularly for those who either believed that future drought would decrease or that it would stay the same as of the first wave of the survey. That is, survey respondents who did not believe that future drought will increase during the first wave of the survey are much more likely to believe that drought will increase during the second wave, especially if soils were dry in the months leading up to the second wave. In contrast, survey respondents who reported believing that future drought would increase during the first wave of the survey overwhelming continue to hold those beliefs during the second wave of the survey, even when soils were significantly wetter.

The few existing studies that use panel data exploit extreme weather events to show that signalling in the form of extreme events have little impact on climate change beliefs, consistent with an interpretation of confirmation bias. Our findings that even modest climatic signalling shifts belief represent a departure from these studies. One possible explanation is that our sample of farmers, forests, and growers is more invested in climate signalling because they depend on water availability for their livelihoods. Another prospect is that changes in the structure of the survey questionnaire between the two waves underlie part of the move toward scientific consensus. These possibilities raise the need for further research into meaningful signalling and climate belief.

However, if such patterns persist, then the signalling value of soil dryness will eventually lead farmers, foresters, and growers to expect future drought to increase, in line with the scientific consensus that New Zealand will experience more frequent and more severe drought in the future (New Zealand Climate Centre 2014, MfE 2018). That said, Booth et al. (2020) show that farmers and other rural decision makers have relatively short, 5-10-year frames of reference when evaluating soil moisture conditions. If wet conditions in a given place persist over such a period, then updating to the scientific consensus may be stymied. Moreover, while landowners' beliefs may increasingly align with the scientific consensus, future expectations may or may not result in behavioural change. Thus, policy change and public options for adaptation may continue to be necessary to support adaptation to future climate. 


\section{Appendix}

Table 7 Logistic estimates that respondents expect drought to increase in the future as of 2019 as a function of 2017 expectations and change in the New Zealand Drought Index, measured as a continuous variable (column 1) and as the number of soil moisture thresholds crossed (column 2)
Table 8 Ordered logit estimates of future drought expectations as of 2019 as a function of 2017 expectations

\begin{tabular}{|c|c|c|}
\hline & (1) & (2) \\
\hline & $8.85 * * *$ & $10.91 * * *$ \\
\hline$\Delta \mathrm{NZDI}$ & $2.23 * * *$ & \\
\hline Increase $_{17} \times \Delta \mathrm{NZDI}$ & 0.76 & \\
\hline 3/4/5 threshholds wetter & & 0.44 \\
\hline 2 thresholds wetter & & 0.88 \\
\hline 1 threshold wetter & & 0.67 \\
\hline 1 threshold drier & & 1.05 \\
\hline 2 thresholds drier & & $2.14 * *$ \\
\hline 3/4/5 thresholds drier & & $3.13 * *$ \\
\hline Increase $_{17} \times 3 / 4 / 5$ threshholds wetter & & 1.13 \\
\hline Increase $_{17} \times 2$ thresholds wetter & & 0.85 \\
\hline Increase $_{17} \times 1$ threshold wetter & & 0.84 \\
\hline Increase $_{17} \times 1$ threshold drier & & 1.15 \\
\hline Increase $_{17} \times 2$ thresholds drier & & $0.34 *$ \\
\hline Increase $_{17} \times 3 / 4 / 5$ thresholds drier & & 1.61 \\
\hline Constant & 1.12 & 1.00 \\
\hline Observations & 1021 & 1021 \\
\hline Pseudo R2 & 0.178 & 0.187 \\
\hline
\end{tabular}

NZDI is measured as the maximum monthly NZDI between January and June of each year. NIWA (2019a) explains these thresholds in detail. Odds ratios are reported. Statistical significance is based on heteroskedasticity-robust standard errors. $* * * p<0.01, * * p<0.05$, $* p<0.1$

\begin{tabular}{|c|c|}
\hline Decrease $_{17}$ & $4.15^{* * *}$ \\
\hline Increase somewhat $_{17}$ & $5.75 * * *$ \\
\hline Increase a $\operatorname{lot}_{17}$ & $31.45^{* * * *}$ \\
\hline$\Delta$ NZDI & $2.13^{* *}$ \\
\hline Decrease $_{17} \times \Delta$ NZDI & 0.48 \\
\hline Increase somewhat $_{17} \times \Delta \mathrm{NZDI}$ & 0.90 \\
\hline Increase a $\operatorname{lot}_{17} \times \Delta \mathrm{NZDI}$ & 0.48 \\
\hline Cut 1 & -3.31 \\
\hline Cut 2 & 0.048 \\
\hline Cut 3 & 2.09 \\
\hline Observations & 1021 \\
\hline Pseudo R2 & 0.144 \\
\hline
\end{tabular}

NZDI is measured as the maximum monthly NZDI between January and June of each year. NIWA (2019a) explains these thresholds in detail. Odds ratios are reported. Statistical significance is based on heteroskedasticity-robust standard errors. $* * * p<0.01, * * p<0.05$, $* p<0.1$ 
Acknowledgements The idea for this paper originated in conversations with Daniel Osberghaus. We are grateful to NIWA in general and Andrew Tait in particular for making the NZDI data publicly available. And we gratefully acknowledge Pamela Booth for data support.

Author contribution PSB designed the survey and conceptualised the study. PSB and PJW equally contributed to the analysis and presentation of results.

Funding Open Access funding enabled and organized by CAUL and its Member Institutions. Funding to support this research was provided by the New Zealand Ministry of Business, Innovation, and Employment through the Strategic Science Investment FundDeclarations.

Availability of data and material Data required for replicating the results are available from the corresponding author.

Code availability The commands required for replicating the results are available from the corresponding author.

\section{Declarations}

Ethics approval The collection of data used in this analysis was approved by the Manaaki Whenua Social Ethics Review Committee, which follows the guidelines established by the New Zealand Association of Social Science Research.

Consent to participate Participating in the study was voluntary, and the survey included a statement of informed consent.

Consent for publication The statement of informed consent noted that anonymised results would be used in scientific publishing.

Conflict of interest The authors declare no competing interests.

Open Access This article is licensed under a Creative Commons Attribution 4.0 International License, which permits use, sharing, adaptation, distribution and reproduction in any medium or format, as long as you give appropriate credit to the original author(s) and the source, provide a link to the Creative Commons licence, and indicate if changes were made. The images or other third party material in this article are included in the article's Creative Commons licence, unless indicated otherwise in a credit line to the material. If material is not included in the article's Creative Commons licence and your intended use is not permitted by statutory regulation or exceeds the permitted use, you will need to obtain permission directly from the copyright holder. To view a copy of this licence, visit http://creativecommons.org/licenses/by/4.0/.

\section{References}

Akerlof K, Maibach EW, Fitzgerald D, Cedeno AY, Neuman A (2013) Do people 'personally experience' global warming, and if so how, and does it matter? Glob Environ Chang 23(1):81-91

Arbuckle JG, Prokopy LS, Haigh T, Hobbs J, Knoot T, Knutson C, Loy A, A.S., Mase, J. McGuire, L.W. Morton and J. Tyndall, (2013) Climate change beliefs, concerns, and attitudes toward adaptation and mitigation among farmers in the Midwestern United States. Clim Change 117(4):943-950

Austin PC, Brunner LJ (2003) Type I error inflation in the presence of a ceiling effect. Am Stat 57(2):97-104

Bernauer, T. (2013). "Climate change politics". Annual Review of Political Science 16: 421-448 (2013)

Booth P, Walsh P, Stahlmann-Brown P (2020) Drought intensity, future expectations, and the resilience of climate beliefs. Ecol Econ 176:106735. https://doi.org/10.1016/j.ecolecon.2020.106735

Borick CP, Rabe BG (2010) A reason to believe: examining the factors that determine individual views on global warming. Soc Sci Q 91(3):777-800

Brooks J, Oxley D, Vedlitz A, Zahran S, Lindsey C (2014) Abnormal daily temperature and concern about climate change across the United States. Rev Policy Res 31(3):199-217

Brown P (2017). Survey of Rural Decision Makers. https://doi.org/10.7931/J2736P2D 
Brown P (2019). Survey of Rural Decision Makers. https://doi.org/10.7931/hkeq-ax12

Brown P, Daigneault A, Dawson J (2019) Age, values, farming objectives, past management decisions, and future intentions in New Zealand agriculture. J Environ Manage 231:110-120

Brown P, Daigneault AJ, Tjernström E, Zou W (2018) Natural disasters, social protection, and risk perceptions. World Dev 104:310-325

Brulle RJ, Carmichael J, Jenkins J (2012) Shifting public opinion on climate change: an empirical assessment of factors influencing concern over climate change in the U.S., 2002-2010. Clim Change 114(2):169-188

Carmichael JT, Brulle RJ (2017) Elite cues, media coverage, and public concern: an integrated path analysis of public opinion on climate change, 2001-2013. Environmental Politics 26(2):232-252

Cunningham S (2021) Causal inference, the mixtape. Yale University Press, New Haven (Chapter 8)

Demski C, Capstick S, Pidgeon N, Sposato RG, Spence A (2017) Experience of extreme weather affects climate change mitigation and adaptation responses. Clim Change 140(2):149-164

Deryugina T (2013) How do people update? The effects of local weather fluctuations on beliefs about global warming. Clim Change 118(2):397-416

Diggs, D.M. (1991). "Drought experience and perception of climatic change among Great Plains farmers." Great Plains Research 114-132.

Drews S, Van den Bergh JC (2016) What explains public support for climate policies? A review of empirical and experimental studies. Climate Policy 16(7):855-876

Egan PJ, Mullin M (2012) Turning personal experience into political attitudes: the effect of local weather on Americans' perceptions about global warming. The Journal of Politics 74(3):796-809

Goebbert K, Jenkins-Smith HC, Klockow K, Nowlin MC, Silva CL (2012) Weather, climate, and worldviews: the sources and consequences of public perceptions of changes in local weather patterns. Weather, Climate, and Society 4(2):132-144

Hassan E (2005) Recall bias can be a threat to retrospective and prospective research designs. The Internet Journal of Epidemiology 3(2):1-7

Hertwig R, Barron G, Weber EU, Erev I (2004) Decisions from experience and the effect of rare events in risky choice. Psychol Sci 15(8):534-539

Hornsey MJ, Harris EA, Bain PG, Fielding KS (2016) Meta-analyses of the determinants and outcomes of belief in climate change. Nat Clim Chang 6(6):622-626

Kamber, G., C. McDonald and G. Price (2013). "Drying out: investigating the economic effects of drought in New Zealand". Reserve Bank of New Zealand Analytical Note series, June.

Konisky DM, Hughes L, Kaylor CH (2016) Extreme weather events and climate change concern. Climactic Change 134(4):533-547

Li Y, Johnson EJ, Zaval L (2016) Local warming: daily temperature change influences belief in global warming. Psychol Sci 22(4):454-459

Lorenzoni I, Pidgeon NF (2006) Public views on climate change: European and USA perspectives. Clim Change 77(1):73-95. https://doi.org/10.1007/s10584-006-9072-z

Milfont T, Wilson MS, Sibley CG (2017) The public's belief in climate change and its human causes are increasing over time. PLoS ONE 12(3):e0174246. https://doi.org/10.1371/journal.pone.0174246

Ministry for Business Innovation and Employment (MBIE) (2016). Rural broadband initiative, phase 1. Report accessed on 8 December 2019 at: https://www.mbie.govt.nz/assets/0b55b27a15/rural-broad band-initiative-phase-1-august-2016.pdf

Ministry for the Environment (MfE) (2018) Climate change projections for New Zealand: atmosphere projections based on simulations from the IPCC Fifth Assessment, 2nd edn. Ministry for the Environment, Wellington

Ministry for Primary Industries (MPI) (2019). "Dealing with drought conditions" Accessed 15 January 2020 at https://www.mpi.govt.nz/protection-and-response/responding/adverse-events/dealing-withdrought-conditions/

Mol A, Tait A, Macara G (2017) An automated drought monitoring system for New Zealand. Water and Climate 37(1):23-36

Myers TA, Maibach EW, Roser-Renouf C, Ackerlof K, Leiserowitz AA (2013) The relationship between personal experience and belief in the reality of global warming. Nat Clim Chang 3(4):343-347

New Zealand Climate Centre. (2014). "Climate change: IPCC Fifth Assessment Report, New Zealand Findings". Accessed 20 January 2020 at https://niwa.co.nz/sites/niwa.co.nz/files/NZCCC\%20Summary_ IPCC\%20AR5\%20NZ\%20Findings_April\%202014\%20WEB.pdf

New Zealand Institute for Water and Atmospheric Research (NIWA) (2017). "Annual climate summary: 2017'. Accessed 9 January 2020 at

https://niwa.co.nz/sites/niwa.co.nz/files/2017_Annual_Climate_Summary_FINAL2.PDF 
New Zealand Institute for Water and Atmospheric Research (NIWA) (2019a). "New Zealand drought index and drought monitor framework". Accessed 15 January 2020 at https://niwa.co.nz/sites/niwa.co.nz/ files/NZDI_more_info.pdf

New Zealand Institute for Water and Atmospheric Research (NIWA) (2019b). "Annual climate summary: 2019b”. Accessed 9 January 2020 at https://niwa.co.nz/sites/niwa.co.nz/files/2019b_Annual_Climate_ Summary_FINAL.pdf

Osberghaus D, Demski C (2019) The causal effect of flood experience on climate engagement: evidence from search requests for green electricity. Clim Change 156(1-2):191-207

Osberghaus, D. and C. Fugger. (2019) "Effects of extreme weather experience on climate change belief". Paper presented at the 2019 annual conference of the European Association of Environmental and Resource Economists, 26-29 June 2019, Manchester.

Palm R, Lewis G, Feng B (2017) What causes people to change their opinion about climate change? Ann Am Assoc Geogr 107(4):883-896

Pourzand, F. and I. Noy (2018). "Impacts of drought on agricultural productivity and profitability in New Zealand: a micro study". Paper presented at the $63^{\text {rd }}$ AARES Annual Conference, Melbourne Victoria, Australia, 12-15 February 2019.

Rabin M, Schrag JL (1999) First impressions matter: a model of confirmatory bias. Quart J Econ 114(1):37-82

Slegers MF (2008) 'If only it would rain': farmers' perceptions of rainfall and drought in semi-arid central Tanzania. J Arid Environ 72(11):2106-2123

Spence A, Poortinga W, Butler C, Pidgeon NF (2011) Perceptions of climate change and willingness to save energy related to flood experience. Nat Clim Chang 1:46-49

Statistics New Zealand. (2012). Agricultural census. 2012. Available online: http://www.stats.govt.nz/ browse_for_stats/industry_sectors/agriculture-horticulture-forestry/2012-agricultural-census-tables. aspx

StatsNZ (2017). “Agricultural production statistics: June 2016 (final)”. Accessed 22 January 2020 at https:// www.stats.govt.nz/information-releases/agricultural-production-statistics-june-2016-final

Stehr N (2015) Climate policy: democracy is not an inconvenience. Nature 525:449-450

Svoboda, M., D. LeComte, M. Hayes, R. Heim, K. Gleason, J. Angel, B. Rippey, R. Tinker, M. Palecki, D. Stooksbury, D. Miskus, and S. Stephens (2002). "The drought monitor". Bulletin of the American Meteorological Society, August: 1181-1190.

Taylor A, Bruine de Bruin W, Dessai S (2014) Climate change beliefs and perceptions of weather-related changes in the United Kingdom. Risk Anal 24(11):1995-2004

Van Boven, L. and G. Loewenstein (2005). "Empathy gaps in emotional perspective taking. other minds: how humans bridge the divide between self and others." New York, NY, US, Guilford Press: 284-297.

Vainio A, Paloniemi R (2013) Does belief matter in climate change action? Public Underst Sci 22(4):382-395

Viscusi WK, Zeckhauser RJ (2015) The relative weights of direct and indirect experiences in the formation of environmental risk beliefs. Risk Anal 35(2):318-331

Wahlquist, A. (2003). Media representations and public perceptions of drought. Beyond drought: People, policy and perspectives, 67-86.

Weber EU (2006) Experience-based and description-based perceptions of long-term risk: why global warming does not scare us (yet). Clim Change 77(1-2):103-120

Whitmarsh L (2008) Are flood victims more concerned about climate change than other people? The role of direct experience in risk perception and behavioural response. J Risk Res 11(3):351-374

Yan N, Wu B, Boken V, Chang S, Yang L (2016) A drought monitoring operational system for China using satellite data: design and evaluation. Geomat Nat Haz Risk 7(1):264-277

Zaval L, Keenan EA, Johnson EJ, Weber EU (2014) How warm days increase belief in global warming. Nat Clim Chang 4(2):143-147

Publisher's note Springer Nature remains neutral with regard to jurisdictional claims in published maps and institutional affiliations. 